Rapporter från Åldrande och Social Förändring No. 3

\title{
The Potentials of Research and Policies on Active Ageing: From MOPACT and EXTEND to EIWO
}

EIWO Working Paper No. 2

\section{Gerhard Naegele}

${ }^{1}$ TU Dortmund University, Germany

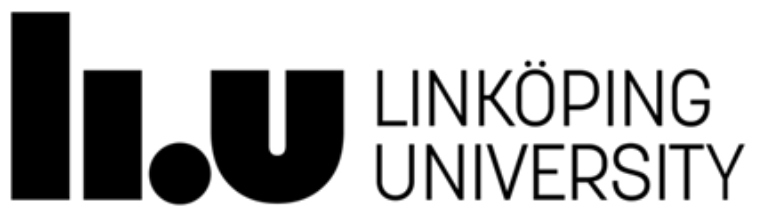




\section{EIWO \\ Exclusion and Inequality \\ in Late Working Life}

Rapporter från Åldrande och Social Förändring No. 3

The Potentials of Research and Policies on Active Ageing:

From MOPACT and EXTEND to EIWO

Gerhard Naegele

Department of Culture and Society

Division of Ageing and Social Change

Linköpings University, SE-581 83 Linköping, Sweden

Linköping 2021 


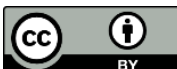

This work is licensed under the Creative Commons Attribution 4.0 International License. To view a copy of this license, visit http://creativecommons.org/licenses/by/4.0/.

Publisher: Linköping University Electronic Press 2021

ISBN 978-91-7929-150-1 (PDF)

https://doi.org/10.3384/9789179291501 


\section{Contents}

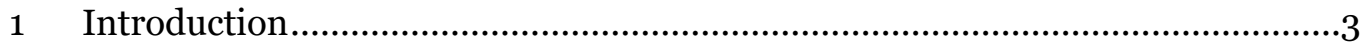

2 MOPACT, WP3 (3/2013-2/2017) ………….................................................

2.1 The mission of MOPACT WP 3 - 'Extending working lives' ....................4

2.2 The political and societal context ............................................................

2.3 Research organisation and research areas ............................................5

2.4 Selected results and policy recommendations .......................................6

$2.5 \quad$ Summary and context-classification .......................................................

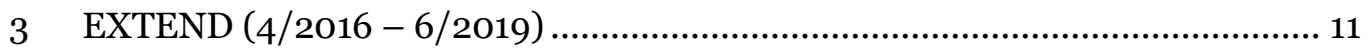

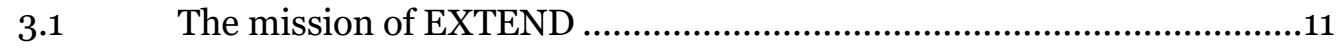

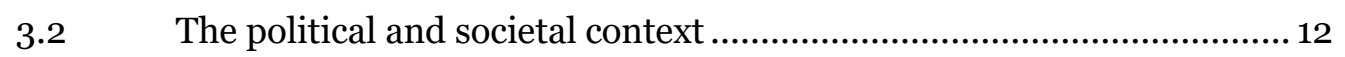

3.3 EXTEND's prime working hypothesis................................................... 13

$3.4 \quad$ Research organisation and research areas .......................................... 14

3.5 Selected results and policy recommendations .................................... 15

3.6 Summary and context classification....................................................... 19

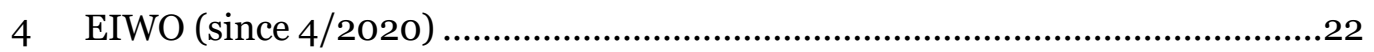

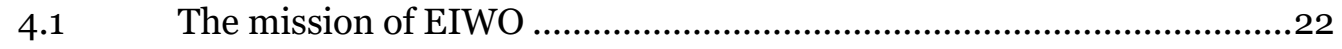

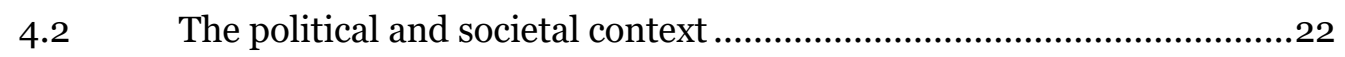

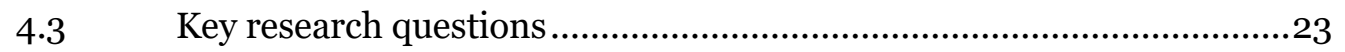

4.4 Key working hypothesis and theoretical classification...........................24

4.5 Research organisation and research projects........................................25

4.6 Interim context classification and scientific and/or preliminary political expectations ...................................................27

5 Overall summary and (interim) conclusions .................................................29

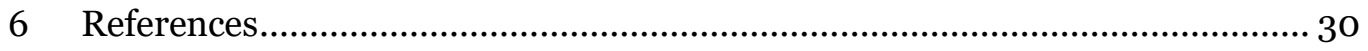

The research programme EIWO is funded by the Swedish Research Council for Health, Working Life and Welfare, grant no. 2019-01245. More information on the research programme and the programme consortium can be found at http://www.eiwoproject.org/.

EIWO Working Papers can be downloaded from the programme's website at http://www.eiwoproject.org/publications.html. 


\section{Introduction}

EIWO - 'Exclusion and inequality in late working life: Evidence for policy innovation towards inclusive extended work and suitable working conditions in Sweden and Europe' (start 2020) - is the third project in a series of interdisciplinary projects on 'ageing in the world of work'. EIWO is being carried out in selective EU-member states that have dealt with how the measuring of 'success and failure factors' can be used to extend working life (EWL) at the various levels (micro, meso, and macro).

The author of this text is involved in all three projects: work package leader for MOPACT WP 3, principal investigator for EXTEND, and scientific advisor for EIWO. MOPACT WP 3 - Mobilisation the potential of active ageing: Extending working lives (2013 - 2017) - compared EU-wide efforts to extend working life with respect to 'good practices' on all levels and served as a starting point for EU-wide recommendations for action. EXTEND - Social inequalities in extending working lives of an ageing workforce: Old and new social inequalities in age-related occupational retirement and pension transitions (2017 - 2019) - focused on social inequalities in the transition phase to retirement and therefore implicitly on socially-selected possibilities and chances of realising a longer working life, including, for example, the professional care sector. EXTEND's recommendations for action related primarily to preventive measures, above all securing and promoting employability to avoid emerging and/or deepening social inequalities mainly through involuntary/forced early exit. EIWO explicitly takes a life course perspective into account to better recognise and classify exclusion from and social inequalities in the late phases of employment biographies, which have been less pronounced in both MOPACT WP 3 and EXTEND, but with leading insights.

This paper places these three projects in an overall context and draws relevant conclusions from the EIWO research perspective aimed at understanding a 'social life course policy' that considers employees' biographies and therefore explicitly a gender perspective as reference points. 


\section{$2 \quad$ MOPACT, WP3 (3/2013-2/2017)}

\subsection{The mission of MOPACT WP 3 - 'Extending working lives'}

MOPACT aimed to support a new paradigm of ageing based on active and healthy ageing. ${ }^{1}$ MOPACT's mission was 'to concentrate the highest possible quality of scientific analyses into the development of innovative policies and approaches that can assist public authorities and other key actors at all levels in Europe to make longevity an asset for social and economic development'. ${ }^{2}$ Thus, the project aimed at supporting the goals set by Horizon 2020 and the European Innovation Partnership in Active and Healthy Ageing to increase average healthy life expectancy across the EU through a series of policies, practices, service developments, product developments, and innovations required to support this aim. MOPACT aimed to develop the research and practical evidence to ensure Europe's ageing population is an asset to society and the economy. ${ }^{3}$

\subsection{The political and societal context}

The macro and micro societal starting points of WP 3 can be summarised as follows:

- Ageing and shrinking of the workforce endanger economic growth and wealth and lead to severe skill shortages in some countries and industries.

- There is a strong risk of dissipated and unused ageing human capital.

- Economic risks refer to both the financial sustainability of the welfare state in general as well as the so-called 'great generational contract' in addressing generational conflicts in the distribution of public goods.

- However, the old-age dependency ratio tends to overestimate the fiscal problems of population ageing, because it merely depicts the age ratio and overlooks the chances to influence the cost development by raising the retirement ages and improving the longer use of the human capital of older workers (Bäcker, Naegele \& Bispinck 2020, vol I).

- Early and involuntary exit from paid work reduces income after retirement and often exacerbates financial problems in old age.

- From a macro-economic perspective, early retirement can also be seen as a risk because it often leads to a weaker age-specific demand resulting from lower old age income among the retired.

\footnotetext{
${ }^{1}$ Following the multi-dimensional concept of active ageing advanced by the WHO (2002).

${ }^{2}$ For the final report on MOPACT see Walker, A. (ed.) (2019): The Future of Ageing in Europe. Making an Asset of Longevity. Palgrave Macmillan. Singapore.

${ }^{3}$ For the final report on MOPACT see Walker, A. (ed.) (2019): The Future of Ageing in Europe. Making an Asset of Longevity. Palgrave Macmillan. Singapore.
} 
- Although there are promising success rates in many countries and industries, activity rates of older workers in many countries are still low, particularly in Central and Eastern European (CEE) countries.

- Extending work in old age might also benefit older workers (economically and intrinsically), although the effects on health status are ambiguous and unclear.

- However, strong differences between 'front-runner' ('early movers') countries and 'late mover' CEE countries must be considered.

- To trust in the effects of individual endeavours alone might overburden many older people/workers and their private networks and lead to social inequalities.

- Policy efforts are required to improve 'active ageing' in the different areas of policy addressed in MOPACT, including work package 3 ('active ageing in employment'), and therefore usable as a way to measure and support EWL.

- Successful sustainable ageing requires, in addition to self-responsibility, enabling structures (promotive and supportive framework conditions).

- National policies are obliged to support ageing individuals to maintain and promote their potentials for active ageing ('subsidiarity principle' and 'capability approach').

\subsection{Research organisation and research areas}

MOPACT WP 3 included 29 partners in 13 EU countries (including 5 CEE countries). In all, a total of 42 researchers from many fields were deployed under the scientific direction of The Institute of Gerontology at the TU Technical University of Dortmund and under the author's leadership (Figure 1).

The research was based on a mix of methods, including literature and policy documents review, secondary analyses of EU-wide survey data, more than 155 case studies of 'promising' (good) practices mainly at the company level in partner countries, which served for 21 more in-depth case studies, and many individual and focus group interviews with older workers, experts with different professional backgrounds, and representatives of social partners, supported by external expertise (scientific board). In all, ten major deliverables were produced (comprising more than 2200 pages of text) (http://mopact.group.shef.ac.uk/). ${ }^{4}$

4 For the final report on WP 3 see: Naegele, G. \& Bauknecht, J. (2018): Strategies ('Action Plan') for Extending Working Lives. Raising Older Worker's employment rates and intensifying Life-Long Learning in later working Life. MOPACT final report on WP 3. Dortmund: Institut für Gerontologie. A shorter version can be found in Walker, A. (ed.) (a.a.O: 107142). 
Figure 1. Countries involved and partners' responsibilities in MOPACT WP 3

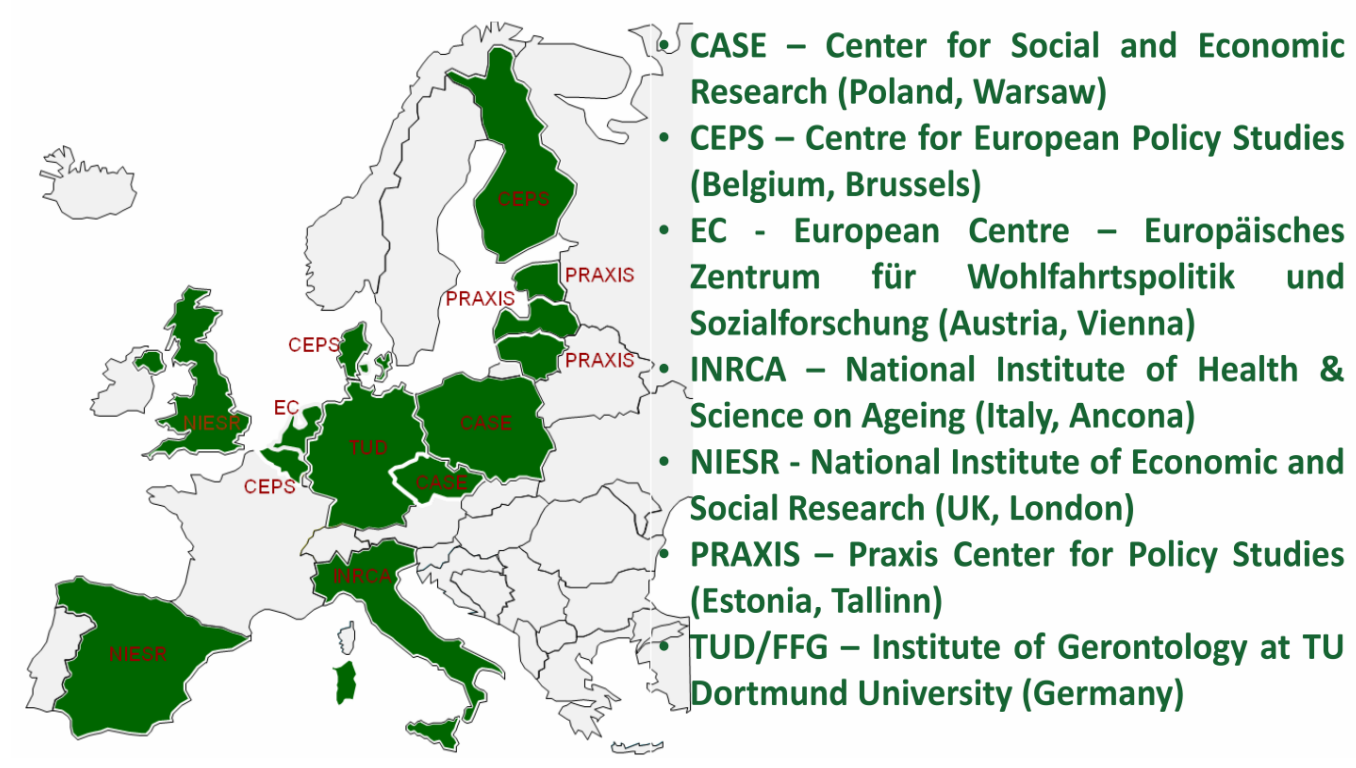

The MOPACT WP 3, 'Extending working lives', was used to address the two overarching research questions:

(1) How can working lives be extended (EWL) and work volume increased while raising the employment rate of older workers below and above legal retirement age, including the unemployed, each aided by lifelong (vocational) learning (LLL)?

(2) What are innovative, effective, sustainable, and transferable private and public-sector measures and strategies that enable and encourage older workers and the unemployed to stay fully employed (pre- and postretirement age) and to engage in lifelong (vocational) learning?

\subsection{Selected results and policy recommendations}

The respective research results were translated into policy pointers, which were incorporated into practice recommendations. The following selection addresses three levels of responsibilities: (1) the national policy level including the level of social partners; (2) the company level; and (3) the level of LLL activities. In all, MOPACT WP 3 produced more than 150 singular policy- and practice-oriented recommendations in 13 single country reports, which are summarised below.

Public policy and social partner level

Active labour market policies

Key actor groups including the ageing population itself and especially the 'active ageing' population must invest in their human capital and allow older people to stay longer in working life. Different groups of key actors need to be addressed. Although 
policy-mix measures have the greatest effects on labour markets, national information and awareness programs are helpful, but not decisive.

In most cases, anti-age discrimination legislation only leads to additional moral effects but rarely provides any practical improvements. Active labour market approaches such as wage subsidies need to be expanded because they are crucial to integrating older unemployed workers, who are mostly long-term unemployed. Moreover, it is possible to balance the competing goals of providing social insurance against adverse health shocks for older workers and maximising their work efforts during late careers. In many cases, supported work despite illness must be given preference over early retirement due to illness.

The disability policy experiences in some EU member states (e.g., Sweden) demonstrate a considerable potential to keep workers with disabilities employed by eliminating or delaying their use of disability benefits and by implementing prowork policies that require employers to improve work environments and rehabilitation efforts. Likewise, it is essential to explicitly disconnect long-term unemployment insurance programmes from disability insurance policies to effectively reduce long-term-unemployment among older workers and to improve employment prospects of persons with disabilities.

Partial retirement schemes enhance quality of work for many people in later phases of working life and allow better opportunities for reconciling work with private needs and interests. However, these schemes are not tried and tested instruments for EWL nor for extending work volume, unless they are explicitly supported in this function in the workplace. Work after retirement ('silver work') should be enabled when desired, but experiences so far show mostly socially selective distributional effects with intrinsic (and not as expected financial) motives being the dominant reasons for this work. However, in view of increasing financial necessity, their importance will grow in the future for more and more pensioners. Many national programmes promote self-employment of older workers but with only small effects.

\section{Adjusting official retirement ages}

To respond to the demographic challenges, many actors recommend adjusting existing pension systems by raising retirement ages and removing early exit pathways. However, there is much empirical evidence confirming socially selective take up rates as better qualified and/or healthy older workers benefit ${ }^{5}$ '[e]specially in countries with little employment support, those with unstable work careers, employment interruptions and few financial resources are at a high risk of being crowded out from late career employment and thus from the possibility of ensuring a decent standard of living' (Hofäcker 2015: 1529).

\footnotetext{
${ }^{5}$ This is one of the prime research interests also in the EXTEND project (see section 3.)
} 
Pension policies primarily aim at encouraging employees to work longer through financial incentives, but these policies have limited success if not strategically linked to supportive corporate workplace policies. Financial incentives have the weakest effect among those older workers bearing objectively the highest financial need to work longer. To unfold the full potential of financial incentives, they need to be supplemented with pro-employability measures in companies.

The corporate level

- Companies play an outstanding role in promoting longer working lives, among them SMEs with special needs for support.

- However, there are still far too few companies with explicit age/ageing management practices and experiences. Furthermore, the distribution favours larger and large enterprises. In other words, a large part of the existing demand is not covered.

- Age/ageing management needs to be linked with the concepts of workability/employability as the best points of departure, however, with different foci in 'early' and 'late mover countries'.

- Collective agreements are helpful in facilitating respective approaches and measures; however, they risk excluding the non-protected businesses and/or employment groups. ${ }^{6}$

- Companies' actions highly depend on HR leaders' ideas and attitudes and need the active involvement of works councils and 'end users' as 'coproducers'.

- To be successful, a corporate 'demographic-sensitive' culture is crucially needed for conscious corporate age management.

Country-group specific conclusions and recommendations for the corporate level

- In 'front-runner' countries, work-related attitudes and values of older workers in terms of quality of work, quality of life, and work-life-balance significantly influence the positive attitudes towards EWL (with increasing importance for women, e.g., work and care, and/or qualified older workers).

- At best, respective measures should be embedded in a 'life-course orientation'.

- In 'late mover' countries, typical work-related employment risk factors (not only for older workers) are still significant (e.g., bad health, lack of skills, and bad working conditions) and therefore often in fact contradictory to realizing EWL.

- In 'front-runner' countries, typical work-related risk factors have not disappeared, particularly in manufacturing sectors and among the typical 
'problem groups' (e.g., the 'double-burdened' - women who are older migrant workers).

- For 'front-runner' countries, special employment risks in the social services sectors (increasingly burnout problems) and with increasing speed in the context of 'work 4.0' (digitised work) need to be looked at more deeply.

- As psychological burdens and mental health problems among older workers are on the rise in all countries, preventive programs are needed.

- Dissemination of 'good practices' is helpful in both country types.

The level of $L L L$

- The issue of LLL is increasing in importance in all countries, but in 'late mover' countries there is a greater backlog demand.

- LLL is a crucial guarantor for the improvement of the workability and employability of an ageing workforce.

- LLL is helpful in the transfer of skills and preparation of critical working-lifetransitions.

- The front-bias of vocational learning should be overcome in ageing societies.

- LLL should have a practical orientation, particularly for older workers.

- In 'front-runner' countries, the practical dominance of the Mathew principle has to be overcome.

- Collective agreements can help increase LLL activities.

- This also applies to awareness and information campaigns.

- 'The vicious cycle between retirement and low training investments in older workers has to be interrupted' (quotation from the Italian country report).

\subsection{Summary and context-classification}

Strongly application - and solution-oriented - however, more in the breadth and less in the depth

MOPACT WP 3 is predominantly an application- and solution-oriented project. One of the greatest merits is providing an overview of the nature and selective dissemination of measures and approaches promoting EWL with the implicit aim of testing the transferability of 'good' and 'innovative' practice to other employment situations and/or to other countries ('lessons to be learnt'). WP 3 recognizes EWL as a necessary 'answer' to diverse economic, financial, and societal challenges confronting nearly all industrialised nations, and demographic change is the primary catalyst. EWL is certainly one of the most important policy pointers of MOPACT WP 3 as it emphasises that government incentives (such as retirement age increases, closing early exit pathways or financial subsidies to individuals and/or enterprises) alone are not sufficient to bring about a turnaround in EWL practice if 
they are not underpinned by a corresponding company-based employment promotion policy.

When MOPACT WP 3 was conceived, the pressure that the labour market exerted on the demand for skilled labour was not as pronounced as it is today. In all societal groups concerned, the conviction is growing that it is worthwhile to invest in the human capital of an ageing workforce. At the company level, the special responsibility for developing the human capital of an ageing workforce is being realised and therefore EWL had already started when we began our research and applies even more today. In addition, the importance of lifelong learning, which is otherwise only marginally addressed in older worker research, is convincingly addressed in WP 3 . The differences in the respective lifelong learning policies and approaches between the so-called 'front-runner' and the 'late mover countries', the latter mainly EEC countries, which still largely exist, are highlighted and the resulting 'deficits' are addressed, explained, and underpinned with concrete policy recommendations.

\section{Respecting differences between EU member states}

In many respects, MOPACT WP 3 fulfilled the expectations of the programme by pointing out the need for action and presenting solutions and 'good practice' with concrete transfer potential for different user groups and different country environments. However, both the growing service sector, especially the social and health sector, and the increasing new employment risks in the wake of introducing digitalisation (work 4.0) have not received the attention they deserve. Based on the eligibility criteria in the call, WP 3 is more broad than deep. If critics and other 'connoisseurs of the scene' point to too little innovative potential in the WP 3 recommendations, then this is primarily due to the empirical foundation we encountered (mainly the 'state of the art').

\section{Few impulses in a truly 'innovative' sense}

Most of the measures and approaches investigated are neither really 'new' nor really 'innovative'. During the research phase, real 'innovations' in the sense of a genuine understanding of novelty were and still are too few in this policy field. Nevertheless, WP 3 researchers (although in rather rare cases) have encountered the following 'innovative' measures: trade union collective bargaining policies, integrated ('intelligent') policy and actor mix approaches, new company initiatives to better reconcile work and care, immediate work-related learning offers for older workers unaccustomed to learning, taking explicitly notice of family and private life obligations (in the sense of a corporate life-course approach) in personnel policy, intelligent and/or socially embedded gliding retirement schemes and similar approaches. Furthermore, most recent WP 3 research have encountered less of the classic standard repertoire of older worker policies.

On the other hand, MOPACT WP 3 has a strategic importance in terms of identifying research questions for future projects (such as EXTEND or even EIWO). There is no need to reinvent the wheel when it comes to addressing the state of the art in future older worker research projects. However, the COVID-19 pandemic 
could cause even more damage here. In the meantime, not the least because of the pandemic, the affectedness of new (and old!) employment risks have been extended to more and more groups of employees and older workers have become one employment risk group among many.

\section{Theoretical foundation with limitations for preventive, cause-related} recommendations

It is one of the honesties in the MOPACT WP 3 assessment to stress that a theoretical grounding stood not in the foreground of this research approach. Moreover, this research focus is more on analysing and interpreting welfare systems' specific approaches, solutions, corporate and individual cultures, experiences, and other features, perhaps because of the strong policy orientation in the philosophy of the overall MOPACT project. In addition, when MOPACT WP 3 started, little theory had been formulated related to older workers and their needs, so WP 3 researchers had little theoretical material to use. This is particularly true for the social inequality debate, which is increasingly coming into focus in the last years, which already appears in WP 3 at one point or another but was not explicitly made as a research focus. This naturally reduced the chances to develop targeted, preventive, and cause-related recommendations and policy pointers. This also applies to relevant country specific features in older worker policies in the different European welfare systems, especially in the EEC countries, which could provide a better political science classification of the WP 3 findings than the WP3 researchers could do. Here, the follow-up projects EXTEND and EIWO undoubtedly could go further. Nevertheless, $\mathrm{WP}_{3}$ laid important foundations for this, because it already revealed the socially-problematic distribution and utilisation structures in many places with relevant differences among the WP 3 countries studied, which deserved both to be examined more closely as well as considered in both recommendations and policy pointers.

\section{$3 \quad \operatorname{EXTEND}(4 / 2016-6 / 2019)$}

\subsection{The mission of EXTEND}

EXTEND - Social inequalities in extending working lives of an ageing workforce is one of five projects that were awarded to a consortium of seven research institutions from five EU member states within the framework of the first call of the EU Joint Programming Initiative (JPI) 'More Years, Better Lives - The Potential and Challenges of Demographic Change'. EXTEND’s prime socio-political rationale is the current retirement and pension policies in most EU-member states with their strong focus on raising retirement ages and financially incentivising those who do and financially penalising those who do not. Thus, the focus is on growing social inequalities benefiting those most able and disadvantaging those unable to realise 
EWL. One funding requirement was the participation of a certain number of EU member states with sufficient experience with the project goals articulated in the call for proposals, which at the same time should have a high level of employment of older workers. The corresponding project partner countries were Denmark, Finland, Germany, the Netherlands and the United Kingdom.

The focus of EXTEND was on social inequalities in the transition phase to retirement, which had until previously been a research desideratum in Germany as well as in many EU comparisons. That is, EXTEND contributes to a comparatively new debate on 'fairness/unfairness challenges' in pension and retirement policies7 (Sinclair, Moore \& Franklin 2014; Phillipson 2018):

Extending working life has very different implications for different groups, who may be affected by many factors including health, domestic and caring responsibilities, migrant status, social position and gender. Those who have worked in heavy manual occupations are more likely to suffer health problems, and have lower life expectancy, but are often treated in the same way in policies to extend working life. Research is needed into how different social and occupational groups are impacted by extending working life, and into how individuals cope with the resulting pressures and opportunities, including how these changes affect the experience of retirement itself. ${ }^{8}$

Consequently, EXTEND's application presents the following hypothesis: 'EWL measures introduced in most EU member states carry the risk of not only generating new social inequalities, but also exacerbating those social inequalities that already existed during the entire previous working life or even increasing them in their cumulative effects'.

\subsection{The political and societal context}

Until the mid-1990s, the labour force participation of older workers in most European countries was characterised by the so-called 'de-occupationalisation of old age', mostly promoted by various public and corporate incentives for an 'as early as possible' exit from work (e.g., by explicit public, sector and/or corporate early retirement programmes, public early exit options in cases of long-term unemployment, and/or by premature reduction in earning capacity due to disability (Naegele 2021). This trend has been reversed since the turn of the millennium towards an extension of working life (EWL) and/or delayed retirement. Since then, the political goals have included encouraging older workers to work longer and

\footnotetext{
${ }^{7}$ This discussion has been going on in social gerontology for a long time. Examples include Naegele (1992) and Walker (ed.) $(2011,2018)$

${ }^{7}$ Page 4 of the first call of the Joint Programming Initiative 'More Years, Better Lives' - The Potential and Challenges of Demographic Change'.
} 
more. Most experts and political decision-makers (UN, OECD, EU, national, scientific discourse) have seen this paradigm shift as an urgently needed reaction to the interaction of different irreversible demographic megatrends and their respective macro- and microeconomic effects (Bauknecht \& Naegele 2015; Naegele \& Bauknecht 2018, 2019).

In this context, EXTEND's primary goal was to examine potential social inequalities in the possibilities and limitations of realising EWL. At the same time, socio-political recommendations for the avoidance and/or compensation of problematic effects should be given in accordance with the explicit mandate for 'solution orientation' in the call. EXTEND's central research hypothesis, mentioned above, corresponds to this.

The most important reference points of EXTEND were fundamental changes in recent state pension, age limit, and/or company employment policies and practices with the primary goals of closing existing early retirement options (i.e., to complicate them and/or make them less attractive financially) and raising the retirement age. Probably the most prominent of these is the raising of the statutory retirement age (in Germany the age of retirement is now 67), which in some countries has also been linked to life expectancy. All these measures are in practice mostly linked to financial incentives to work longer or, turned the other way around, to add financial sanctions for those who do and cannot do so for various reasons. In addition, active labour market programmes have been initiated in many countries and lifelong learning (LLL) measures have been intensified (Bauknecht \& Naegele 2015; Naegele \& Bauknecht 2018, 2019).

\subsection{EXTEND's prime working hypothesis}

When EXTEND started, this paradigm shift was insufficiently investigated with regard to its social implications, especially with regard to social inequalities in the living conditions of older workers. They were the prime point for the central research questions of EXTEND, which aimed to test the following central working hypothesis:

The paradigm shift often takes place at the price of growing social inequalities. It is mainly those employees who are able to work longer who benefit, whereas those who are not able to do so, for whatever reason, are disadvantaged in various dimensions of their life situation.

EXTEND's focus was on socially unequally distributed retirement structures and their underlying socially different employment opportunities among older workers, which (at least for the EXTEND partner countries) could partly already be confirmed earlier by MOPACT WP 3 (Naegele \& Bauknecht 2018, 2019). These include the unequal distribution of early and later (i.e., forced and voluntary retirement) and long-term unemployment among older workers as well as profiting from rising employment rates, conducive components of workability and/or employability, profiting from corporate age management ('good practices' and/or respective collective agreements) or differences in pre- and post-retirement health 
as a driving determinant of forced early exit and as prime dimension of quality of life in retirement.

EXTEND focused on both the social policy-macro level as well as sectoral characteristics and differences and followed the empirically supported thesis that retirement decisions are predominantly influenced by company's working environments - i.e., when they are tied to specific jobs and conditions and 'preprogrammed' at these jobs (Naegele 1992). For example, the social services sector (with a focus on the health and care sector, HCS) was selected as a sector that is affected by demographic change in two ways (an ageing workforce and increasing age-related demand for inpatient care) and where the goal of EWL is particularly difficult to realise.

\subsection{Research organisation and research areas}

EXTEND included seven partners in five EU countries ${ }^{9}$ working together under the scientific direction of The Institute of Gerontology at the TU Technical University of Dortmund. In total, a group of 25 interdisciplinary researchers were involved. Research on MOPACT and EXTEND was based on a mix of methods, including literature and policy document reviews, secondary analyses of survey data, case studies of 'promising' (good) practices mainly at the company level and limited numbers of individual and focus group interviews with older workers as well as expert interviews with policy makers and representatives of social partners, supported by external expertise in a scientific board. In all, ten major deliverables were produced, representing ten work packages. ${ }^{10}$

In the individual sub-projects, the respective manifestations and dimensions of social inequality on the different stages of the retirement process have been investigated. At the same time, EXTEND looked for 'innovative' and socially 'fair' solutions (in the sense of 'good practices') on different levels (macro, meso, micro) that could be suitable not only to improve the overall employability of disadvantaged older workers, but also to enable as many of them as possible to voluntarily retire and therefore make it a 'real' alternative to forced early retirement. In other words, the 'solution orientation' explicitly claimed in the call did not refer to those who were already privileged in their employment opportunities in their earlier working lives.

\footnotetext{
${ }^{8}$ University of Sheffield UK, Aalborg University (Dk), University Medical Center Amsterdam, Institute for Work and Technology (G), Technical University of Dortmund (G), Finnish Institute for Occupational Health (Fi) and Institute of Gerontology at the Technical University of Dortmund (G).

${ }^{9}$ For the final report, see Naegele, G. \& Hess, M. (eds.) (2020): Alte und neue soziale Ungleichheiten bei Berufsaufgabe und Rentenübergang. Ergebnisse des EXTEND Projektes. Wiesbaden: SpringerVS. A short version can be found in Richter, G. (Hrsg.) (2021): Arbeit und Altern. Eine Bilanz nach 20 Jahren Forschung und Lehre. Baden-Baden: Nomos-Verlag: 141-158.
} 
EXTEND took up the following research areas, which were dealt with in each of the partner countries with different focuses:

- Institutional and operational changes in state pension and retirement, labour market, and employment policies related to older workers with potential implications for social inequalities.

- Potential social inequalities in the case of indexing the retirement age according to life expectancy (as practised in Denmark and Finland, but only discussed for Germany so far). ${ }^{11}$

- Connections and interdependencies between health and retirement decisions in the pre- and actual transition phase as well as between health and life situation in the (post) transition and later age phase.

- Reconciliation of employment and care as an (early) retirement reason/motive with special attention to the so-called 'double-duty-carers', i.e., those who care privately and full-time/professionally at the same time.

- Working conditions and work arrangements in their respective inequalityrelevant implications for retirement structures and decisions in the professional care sector (long-term care homes, ambulatory care services, and hospitals).

- 'Good practices' in the avoidance/reduction of social inequalities in career abandonment and retirement transition and their respective cost-benefit relations.

\subsection{Selected results and policy recommendations}

The key findings are summarised below. ${ }^{12}$

Involuntary early retirement as well as the chance to work longer voluntarily and in dignity' are to a large extent socially unequally distributed. In many cases, they follow the theory of cumulative advantages and disadvantages linked to the life course ('cumulative disadvantage theory'; Dannefer 2003): low levels of schooling and vocational training are just as important indicators of low and/or high integration and retention chances of older people in paid employment as a reduced state of health due to the accumulation of work-related burdens in one's employment biography. Particular risks affect older long-term unemployed and older female employees in precarious employment (the latter, e.g., in part-time, temporary, and agency work). Working conditions and workloads, especially in the late phase of working life, vary from sector to sector and have an additional, often

\footnotetext{
${ }^{10}$ But just recently $(6 / 2021)$ proposed again as a 'pension at 68 ', linked to an indexation of life expectancy by the Scientific Advisory Council at the Federal Ministry for Economic Affairs and Energy (BMWE 2021).

${ }^{12}$ See different contributions in Naegele \& Hess (eds.) (2020): a.a.o.
} 
triggering influence. The problematic ('long-distance') effects from a socio-political point of view can be seen in different dimensions of the living situation before and after retirement and often even in old age, above all as lower (old-age) incomes, higher risks of illness, a lower degree of social integration and a lower quality of life overall.

However, there are indications of a decline in the importance of economic and company push factors and state pull factors on the timing of retirement. In contrast, the paradigm shift from early retirement to working longer is increasingly characterised by the simultaneity of 'need' and 'retain' factors, both of which, however, promote EWL with different directional effects. 'Need factors' are mostly caused by the monetary benefit restrictions of early career exit options and thus limited possibilities to early exit from the labour market, forcing many to work involuntarily. In contrast, 'retain factors' describe or encourage voluntary, (i.e., intended) later retirement (Ebbinghaus \& Hofäcker 2013). Typically, these factors are an expression of active company strategies to retain workers as a reaction to a shortage of skilled workers in the company and therefore are mostly promoted by the companies themselves. Accordingly, there are hardly any new hires of older workers from unemployment. In the 'retain context', it is primarily a matter of motivating and supporting the continued work of already employed ('proven') older workers and in rather rare but growing number of cases also beyond the official retirement ages, however, often under changed contractual conditions ('silver worker'). Retainers are primarily interested in those who, due to their qualifications, health, etc., have better employment prospects or more favourable starting conditions for EWL. This can also be seen in the fact that the employment rates of older workers have risen above average in the middle and/or upper qualification groups.

In many EU countries, among them Germany, which along with the Netherlands is one of the 'frontrunners' at EU level, there has been a considerable increase in the employment rates of older people since the beginning of the millennium. However, this development cannot be attributed to clear causal factors (as repeatedly attested to the various government reform programmes and incentives, e.g., Börsch-Supan 2016) but is explained by EXTEND as a complex mixture of several interdependent factors. The most important of these include the generally positive economic situation (except for the financial crisis of 2008/o9), the shortage of skilled labour in companies and the employment-promoting/demand-effective implications of positive cohort effects such as health, qualification, and work motivation. The increasing labour force participation of women and the strong increase in part-time work are also of particular importance. Therefore, work-related changes in the attitudes and behaviour of older people are always the result of various interacting factors, each of which has demonstrably increased in importance during the period observed (Hess, Naegele \& Bauknecht 2020; Jensen 2020).

Health status is a very crucial predictor of both workers who have to stop working early and those who can work longer and thus of the existence of social inequalities in retirement. EXTEND's extensive secondary analyses of national and 
international datasets demonstrate significant inequalities between individuals of low- and high socio-economic status. In this respect, it was confirmed that in many cases 'remote effects' of earlier risky working conditions are effective. At the same time, these are central starting points for measures to reduce health inequalities before and after leaving work. Therefore, improvements in unhealthy working conditions that take the entire life course into account will probably have a positive influence on the health of later cohorts of retirees (and vice versa) and reduce social inequalities in health after leaving work but not completely eliminate them.

The problem of reconciling employment and health care is becoming increasingly explosive in the context of demographic change. Not only are the employment prospects of a growing number of working carers massively affected and therefore their chances of voluntary EWL or sufficient later pension expectations lessened, but also an insufficient reconciliation leads to cumulative multiple burdens and therefore considerable restrictions in their quality of life. With its special focus on 'double-duty carers' (i.e., those who simultaneously provide both professional and private care), EXTEND was also able to show for the first time in Germany that there are new problem groups here with special employment risks and therefore new needs for action that have yet to be recognised by policy-makers and practitioners.

EXTEND confirms the particular stress situation of employees in the professional care sector and therefore a global inequality situation for this sector (Naegele 2015). Involuntary early retirement, often for health reasons, is de facto the 'normal case' here. Social inequalities arise in two ways: in an overall comparison of the sectors of person-related social services and individually and/or group-related within the HCS. The latter occurs mainly because of the lack of or only selective access to internal and external professional development and alternative options. The change from direct care to an administrative activity, which many strive for as a way out of 'hands on care', is only possible for a few, especially those with higher qualifications. This corresponds to the fact that one has to look intensively for company personnel concepts with an explicit life course reference in this sector.

EXTEND was able to show in many places that preventive measures to promote EWL are possible and economical. This is especially true for health promotion measures. The model of 'late-career planning' practiced by the Finnish project partner FIOH (Finish Institute for Occupational Health) and evaluated within the framework of EXTEND (Vuori 2019) could also serve as a model for other countries. Companies that practice age management are also better positioned to recruit qualified workers. In addition, corresponding investments in the human capital of ageing workforces are micro-economically beneficial, measured in terms of productivity increases and other economically relevant indicators.

On the other hand, company age management, demographic collective agreements, etc. are also sources of new social inequalities. It is true that exemplary age management is being practiced in more and more companies, partly, as in Germany, triggered by demographic collective agreements (INQUA 2014). 
Nevertheless, as a rule, those who benefit from this workplaces are covered by such regulations. Employees in sectors and companies without age management and/or without relevant collective bargaining protection entitlements and provisions are not affected. Moreover, in many companies the 'Matthew principle' dominates i.e., corresponding measures preferentially benefit those employees who already have favourable conditions for achieving EWL.

Overall, EXTEND's research leads to the following selected conclusions and policy pointers.

\section{Public policy level}

- To raise public awareness and to pay more attention to social inequalities in retirement and/or pension policies: 'Social inequalities should be a key policy focus' (Walker 2020: 245).

- To be aware of many forms of social inequalities in retirement and among typical 'problem groups'.

- To differentiate retirement and pension policies according to the employability of different older workers groups.

- To be aware of socially distributive effects of those retirement policy suggestions aimed at synchronizing official retirement ages with lifeexpectancy.

- To link prevention and disability policies more effectively and/or strategically.

- To retain socially acceptable early retirement options for 'highly work-loadburdened' workers.

- To focus on financial 'incentives' for EWL at the legal level alone, which are not enough to extend working life on a voluntary basis if not accompanied by corporate HR measures.

- To focus on comprehensive ('multi-level') approaches.

- To combat precarious employment in the pre-retirement phase, particularly among working women.

- To demand and to strengthen the responsibility of companies in terms of promoting EWL.

- To provide more public expenditures for healthy ageing (not only in work but also in the retirement phase) pays off.

\section{Corporate and collective agreement level}

- To ensure '[e]mployers should also recognize social inequality' (Walker 2020: 246).

- To expand company age management and collective bargaining support programmes to strengthen the employability particularly of disadvantaged older workers.

- To identify and reduce stressful/health-endangering working conditions in time. 
- To foster workplace health through extension of corporate preventive health promotion and protection.

- To make special efforts for 'problem groups' by targeted approaches.

- To better use and strengthen those affected as 'experts in their own affairs.

- To combat inequalities particularly in the health and care sector.

- To be aware of new employment and retirement risks through work 4.o.

- To reconcile policy more effectively for private carers at different levels.

- To promote and disseminate 'good practices'.

- To avoid 'Mathew-effects' in corporate and/or collective age management and/or corporate personnel policies.

- To be aware of the risk to exclude unprotected sectors through collective agreements.

- To implement more cost-benefit analyses - 'good practice' pays off.

\subsection{Summary and context classification}

In depth instead of breath - clear focus on social inequalities

While MOPACTs WP 3 went 'broad' with its analyses and recommendations, propagated EWL as a goal for as many as possible, and considered differences in the levels of development between 'front-runner countries' and those that inevitably 'lag behind' (such as many CEE countries), EXTEND explicitly went into depth in two respects. First, EXTEND focused on selected EU member states, but with the aim of disseminating these findings as widely as possible throughout the EU on the problem of the socially selective distribution of retirement and the underlying employment structures, which has recently been discussed under the term 'fairness challenges' (Sinclair, Moore \& Franklin 2014; Phillipson 2018). With its explicit focus on social inequalities, EXTEND has adopted a research perspective that has been called for by many but has not been taken up - at least not with such intensity and scientific prioritisation - in both empirically-oriented older worker research and in retirement and pension studies. Second, EXTEND focused much more explicitly than MOPACT on the development of employment-related disadvantaging risk factors in the previous employment biography, which ultimately lead to an unequal distribution of retirement transitions 'in dignity' and whose effects extend into the late phases of employment and very often also into the post-work phase of life in old age. In this respect, the conclusions and policy pointers drawn in both projects also differ in the respective topics, focal points, and target groups.

Foci on cumulative disadvantage theory and life-situation concept These two perspectives were promoted by the explicit grounding of EXTEND in existing theoretical concepts. While MOPACTs WP 3 research had to remain 'weaker in theory' to adequately capture the 'broad perspective' of all participating countries, EXTEND was from the outset concerned with theory, albeit more in its conceptual underpinning. Two classic theoretical concepts of inequality research 
were directly incorporated. First and foremost, EXTEND considered the cumulative disadvantage theory (Dannefer 2003), which also plays a prominent role in EIWO as prime concept to explain the developmental and emergence level of social inequalities over the life and work course (see section 4.4). Second, EXTEND considered the 'life situation concept' originating from the early German sociopolitical inequality research tradition, which focuses both on the empirical distribution as well as the selective experiences of social inequalities in daily life and their respective interconnectedness during the life and work course (Leßmann 2015; Bäcker, Naegele \& Bispinck 2020; vol. I). EXTEND's explicit focus on 'scopes of action' ('Handlungsspielräume'), embedded in the 'dialectic of individual behaviour and societal contexts' (Amann 1983), is important. The proximity of the historically older life situation concept to more recent approaches such as the agency concept (Hitli \& Kwon 2016; Damman \& Henkens 2017) and/or the capability approach (Sen 1992) is obvious.

Last but not least, it was this theoretical foundation that enabled a theory-based localisation and derivation of EXTEND's commitment to conducting 'solutionoriented' research and the resulting policy pointers/recommendations mentioned earlier. However, EXTEND was not only solution-oriented but also very strongly practice-oriented. Its special focus on the health and care sector, the social risks linked to reconciling work and care, the identification and evaluation of corporate (and other related) 'good practices' as well as, if necessary, the use of case-related cost-benefit analyses stand for an approach that is otherwise rather neglected in sociological research: to combine theory and practice in the interest of the core concern. EXTEND's 'policy priorities' not only address the EXTEND countries but also the EU countries: 'Extend has successfully combined theory and practice in the interest of the core concern' (Walker 2020: 245).

\section{Important side effect - relativising the current 'euphoric' sight on the increase in labour force participation of older workers}

EXTEND could also make an important contribution to relativising the current 'euphoric' debate about the increase in labour force participation of older people that can be observed in many EU countries. In contrast to dominant supplyoriented explanations, one only has to set the right 'screws' (in the sense of financial incentives) to get closer to the goal of EWL. That is, EXTEND provides a basis for a more comprehensive analysis of modern attitudes to work and retirement decisions of older workers based. It could be shown that an isolated consideration of one possible factor alone offers little explanatory power for retirement decisions; rather, it is influenced by a variety of factors that are largely embedded in overarching processes of change in important societal sub-sectors, each of which has a direct and indirect influence (e.g., labour market, companies, families). According to this, changes in the labour market participation of all workers are generally associated with (a) macro-structural changes (overall economic situation, demand), (b) a change in the relevant discourses ('welfare, work or leisure society'; 'active ageing'), (c) structural changes in institutions (welfare state, labour market, family), and (d) changes in individual dimensions of employability and subjective dispositions. 
EXTEND's respective analysis shows that the overall conditions for EWL have both improved and increased. EXTEND proves for the countries under study that only the interaction of these megatrends can explain the complex reality of the increase in employment of older workers that has taken place and is taking place (Jensen 2020; Hess, Naegele \& Bauknecht 2020).

Plea for a multi-level EWL policy with equal attention to all employee groups Against this background, EXTEND recommends that governments should approach the policy objective of EWL at several levels of governance and with equal attention to all employment groups. The first level requires ensuring the important prerequisites for a stable economy and a stable demand for (older) workers. ${ }^{13}$ This should also motivate companies to invest (even more) in the employability of older workers. That is, they should be motivated to design and adapt working conditions and their environments accordingly, for example, through age management measures, health prevention, LLL, and work-life balance measures. Finally, both individual and collective dispositions (e.g., work orientation and motivation to EWL) would have to be changed through comprehensive discourses and new indirect forms of control (e.g., influencing corporate culture and changing negative age stereotypes). It is still central to pay more attention to the special needs and wishes of women relevant to EWL (e.g., different 'compatibility requirements' and special interest in a balanced work-life-balance). In many countries, older women are still an unused labour market resource. To secure voluntary further work in dignity' for newcomers or women re-entering the labour market (e.g., older female job-seekers after previous unemployment), precarious forms of employment should be avoided or eliminated (Jensen 2020).

In this context, to recall the social inequality approach of EXTEND, policies and companies also target older workers who do not have a high level of workability and employability. Although the 'Matthew principle' is more successful at first glance, at least measured by the labour force participation rates, as it is easier to implement, it must not be a primary starting point for EWL-relevant support measures if one considers the 'fairness challenges' mentioned earlier. What is required are comprehensive, 'broad-based' approaches that cover and focus on those with less favourable employment histories and/or EWL prospects as far as possible. Here, the need to catch up and make additional and tailor-made provisions is clearly greatest, and comparatively more time and money must be invested, if only to avoid higher follow-up and late costs (e.g., combating social exclusion and poverty in old age). One of EXTEND's significant final conclusions is that only by focusing on typical

\footnotetext{
${ }^{13}$ However, it was not clear during the term what upheavals the COVID-19 pandemic would bring on the European labour markets. In this respect, EXTEND was carried through with a comparatively favourable starting position in terms of labour market chances for older workers in general. In the meantime, there are again increasing indications that the COVID-19 pandemic upheavals on the labour markets are in many cases also associated with new social inequalities.
} 
'problem groups' will an innovative strategy be developed that appropriately addresses the diverse challenges of demographic and social change.

\section{EIWO (since 4/2020)}

\subsection{The mission of ElWO}

EIWO, Exclusion and inequality in late working life: Evidence for policy innovation towards inclusive extended work and suitable working conditions in Sweden and Europe, focuses on inequality and exclusion in late working life in the workplace and labour market. Like EXTEND, EIWO focuses on inequalities in the transition to retirement. However, with its particular observation of the preceding late phases of working life, EIWO takes a much closer look at the social processes and determinants. EIWO is one of several research programmes funded by the Swedish FORTE ${ }^{14}$ within the funding scheme on 'Working Life related challenges 2019'. Sweden, Germany, the United Kingdom, and Poland participate in EIWO with a total of six renowned research institutions ${ }^{15}$ and a team of about 20 associated researchers with different disciplinary backgrounds (mainly sociology, psychology, social gerontology, and political sciences).

\subsection{The political and societal context}

EIWOs starting point is similar to MOPACT WP3, however, it focuses on the risks of selective attainment of the objective of EWL due to unequal labour market opportunities for certain groups (exclusion) and unequal working conditions in different sectors:

The rapidly ageing societies in Sweden and Europe call for prolonged working lives and for increasing participation of older workers in the labour market. But selective goal attainment with unequal labour market access and increasing exclusion of certain groups as well as in certain industries from late working life creates severe social problems of increasing social inequalities, economic exclusion and marginalisation particularly in late working life stages. ${ }^{16}$

\footnotetext{
${ }^{13}$ Swedish Research Council for Health, Working Life and Welfare (FORTE). FORTE has a national coordination responsibility for research in several research areas.

${ }^{14}$ Institute of Gerontology at the TU Technical University of Dortmund, Technical University of Dortmund, University of Vechta (all Germany), University of Sheffield (UK) and Jagiellonian University of Krakow (P).

${ }^{16}$ Page 5 of the EIWO application.
} 
Clearly, the socio-political orientation of EIWO is more far-reaching than that of the two predecessor projects mentioned. This is also true for the explicit life-course orientation of EIWO, which has been taken up from time to time in earlier research (Naegele 1992; Walker 2006, 2009; Phillipson 2018), but this time it is the core starting point for EIWO:

In parallel, working life is institutionally extended by raising the standard retirement age and losses for those who do not participate increase. On the one hand, this relates to lasting age discrimination on the labour market, with negative age stereotypes and ageist employer policies. On the other hand, it expresses a failure of policy intervention in Sweden and many other European countries. Policies are often simplistic and cross-sectional, and societies fail in developing a systematic long-term and inclusive life course policy. Current policies towards inclusive labour market involvement of older workers have neglected that it is shaped by a variety of contemporary factors on a number of levels (e.g. pension systems, employment regulations, organisational strategies) as well as events and conditions experienced over the entire lives of individuals (e.g. social origin, childhood stresses and strains, labour market entry, unemployment, poverty, migration, illness). They neglect how these factors vary by gender, but it is also class, migration experience and region that play a significant role. ${ }^{17}$

\subsection{Key research questions}

This background and the six EIWO objectives prompt the following key questions, which directly relate to each of the following objectives:

(1) What is the nature, sources, and effects of exclusion and inequalities in extended late working life and pathways into retirement in Sweden and Europe regarding employment access and status, quality of work, tenure, and level of pay and what is the impact of workplaces in terms of employer and sector differences on this?

(2) In what ways are exclusion and inequalities in late working life and their cumulation over time related to contemporary social risks, to changing social policy regimes, to shifting organisational policies and practices, to institutionalised age and gender stereotypes, and to earlier life course and work course risks, experiences, and events?

(3) In what ways do individual biographies shape perceptions of exclusion, inequality and fairness and how does this impact exclusion and labour market participation?

\footnotetext{
${ }^{17}$ Ibid. page 6.
} 
(4) What is the influence of macro-level political, economic, and social differences and ongoing change and how does the Swedish welfare system shape this in comparison to other European countries?

(5) Which combination of policy measures on different levels (micro, meso and macro) promotes integration as well as mitigates exclusion and inequality in late working life?

(6) How can life-long learning be fostered by a life course policy approach on a company, sector, and national level?

\subsection{Key working hypothesis and theoretical classification}

There is a lack of research on the relationship between earlier life course events and risks and other and late working life employment outcomes that extend into later life. This research is essential both for understanding the sources of late working life exclusion and inequality and for informing policy and practice about optimised responses. EIWO aims at achieving a step-change in social theory by bringing together five distinct theoretical perspectives (see Naegele \& Walker 2021):

1) The life course theory (especially gendered life and work courses) is aimed at understanding the processes by which early and midlife conditions, events, and risks influence employment related to inequality in late working life. In doing so, EIWO focuses on gendered life and work courses considering recent approaches acknowledging that work course trajectories are increasingly differentiated, and the full work course needs to be investigated to understand the life course (Moehring 2016; for Sweden see Motel-Klingebiel \& Kelfve 2017).

(2) The cumulative (dis)advantage theory (Dannefer 2003) including the agency concept (Hitlin \& Kwon 2016) suggests that (dis)advantages earlier in the life course entail (dis)advantages later, which strengthens differences in socio-economic resources and status over time. There is much evidence on the negative effects of early life deprivation on later life health and social status, which is also true for typical older worker employment risks and especially for social deprivation of women in later life. At the same time, while early risk factors have a potential bearing on later life outcomes, they do not simply determine them. Key roles are played by individual agents themselves, social relationships, and public policy (Walker 2006). EIWO aims at concentrating on a combination of structural factors, such as social class of origin, early and mid-life deprivation and gender, agency influenced outcomes in youth and adulthood, such as personal investments in education and training, and gendered social policy measures.

(3) With respect to social risk theory (Naegele 1992; Bäcker, Naegele \& Bispinck 2020, vol. I), EIWO aims at filling a large gap in the ageing and social policy literatures by bringing together the theory of cumulative (dis)advantage and the notion of 'social risks' - i.e., risks that are 'beyond the scope of individuals alone to solve'. Major sources of increased risks are the continuing de-standardisation of the life course and employment with its attendant rise in precarity, coupled with the promotion of an activation paradigm that emphasises individualisation in place of 
solidarity. Women have been affected significantly by these changes. Although female employment biographies have altered in recent years, it is still the case that childbirth and childcare, illness of a close relative, and caregiving for older parents mark the beginning of disruptions and discontinuities for many women, conditions that affect decisions concerning labour force exit and the resources they carry onto retirement, such as caring for older relatives.

(4) The concept of intersectionality is also an issue. A prioritisation of gender will be partly delivered via intersectionality theory to ensure that it is located within the real-world complexity of multiple, potentially reinforcing forms of disadvantage. This theory considers overlapping social positions, statuses, and identities and resists simplistic assumptions of causation (Crenshaw 1991). The theory posits that various biological, social, and cultural categories, such as gender, race/ethnicity, class, sexual orientation, religion, and age, interact on multiple levels to reinforce disadvantage.

(5) In a review of comparative social policy regimes, EIWO elaborates on macro structures and dynamics of change to represent the socio-political contexts within which late working lives are now being shaped. Although the notion of welfare regimes and Esping-Andersen's (1990) original typology have been validly criticised, they are still valid starting points for a comparative appreciation of the role of state institutions and welfare systems in growing or diminishing social inequality.

\subsection{Research organisation and research projects}

EIWO includes seven partners in four EU countries, working together under the scientific direction of Linköping University under the guidance of Professor Andreas Motel-Klingebiel. As MOPACT and EXTEND, EIWOs research is based on a mix of methods, including the following:

- Literature and policy documents analysing key labour market, economic, social, and cultural changes within and across the four EIWO countries over the past 25 years.

- Secondary analyses of existing longitudinal data sets like the SWEDISH registry data and/or EU-wide survey data (e.g., SHARE LIFE), which will also be reviewed in an intersectional perspective.

- Case studies at the company level to better understand meso level factors, such as employer's practices and workplace conditions in about 15 public and private sector branches as well as in selected organizations in each of the four EIWO countries.

- Many individual first-hand biographical narrative interviews ( $n=25$ in each of the four EIWO countries with older workers).

- A selected number of expert interviews with policy makers and representatives of social partners.

- Each of them supported by external expertise in a scientific board. 
In all, EIWO researchers are engaged in nine major projects:

- Project I - Dynamics of Late Employment and Life course Policies. This is the core project, which informs projects II-IX by providing theoretical embedding as mentioned in section 3.3.

- Project II - Inequality and Exclusion Risks in Swedish Late Working Life. This project will outline and develop the respective Swedish perspective in the overall EIWO context.

- Project III - Mechanisms and Origins of Late Working Life Exclusion. This project will elucidate basic mechanisms from a biographic perspective, which can be analysed and verified on a broader life course data basis by later projects.

- Project IV - Life courses, Cumulative Inequality and Exclusion Risks in Late Working Life. In the context of the programme's initial theory paper, the main aims of this project are to analyse the nature and sources of inequalities in late working life employment and retirement and to identify individual and family responses and coping strategies.

- Project V - Country Studies: National Policies and Political-Economic Context. The main task is to understand the influence of macro social and political-economic change - economic strategies, including austerity, population dynamics, cultural swings, or social policy trends - on late working life employment exclusion and inequalities and, especially, the extent to which different regimes and combinations of policy areas like health, disability, employment, childcare, and qualification are associated with different forms and levels of inequality.

- Project VI - 'Sectoral and Organisational Policies and Processes. The main task is to examine influences of social policies and structures as well as the contribution of employer's policies and practices on late working life exclusion and inequality.

- Project VII - Good Practice and Effects for Inclusion and Equality in Late Working Life. The main objectives are to develop and analyse an up-to-date portfolio of examples of good practice that consider two goals - maintaining the employability of ageing workers and improving work opportunities over the life course by means of life course-oriented policies.

- Project VIII - Perceptions of Inequality and Fairness. This project, using the qualitative data of project III, aims at exploring how individual trajectories impact perceptions of fairness and inequality and attitudes towards the role of the state in reducing inequalities in late working life.

- Project IX - Acclimation, Leadership or Exceptionalism: Lessons from a European Perspective on Swedish Life Course Policies. In the context of the various outcomes within the programme, this project aims at analysing and discussing challenges and consequences for fostering inclusion and equality in late working life. 


\subsection{Interim context classification and scientific and/or preliminary political expectations}

Solutions and justifying solutions in the sense of a solid life course policy In contrast to MOPACT WP 3 and EXTEND, the expected EIWO findings are not primarily and immediately solution oriented. However, they are likely to be highly suitable for laying the foundations for developing and successfully implementing sustainable preventive policy concepts with the goal, which is in itself highly appealing, of reducing social inequalities and social exclusion in the late phases of working life. This is also true with regard to the goal of extending working life 'in dignity' for as many as possible, including as many as possible of those who today fail to do so for various reasons of disadvantage. EIWO aims to provide the theoretical basis for such a policy, which is directed at the entire life course and therefore securing the theoretical and scientific recommendations as well as preventing as many as possible from being excluded from a satisfactory late phase of gainful employment by becoming a victim of the repeatedly empirically proven 'Mathew principle'.

In this way, EIWO could be an important building block in cushioning the idea of a social life course policy - at least with respect to working life (Naegele 2010), which is already being discussed and pursued in some EU member states as a further development of the institutionalisation of a life course policy at the EU level that has been proposed for some time by social policy makers and academics close to them (e.g., Leisering 2003). For gerontologists, fighting age discrimination, ageism, and negative images of old age requires proactively laying the foundations for more quality of life in old age. In this respect, EIWO is also in the tradition of a critical gerontology, which has been represented for a long time, especially in the UK (Walker 2006).

\section{Convincing, targeted linking of different theoretical approaches}

EIWO has chosen a very demanding and at the same time truly innovative approach in which it, for the first time to my knowledge, provides a targeted combination of previously partially independently treated theoretical approaches: life course theory, cumulative disadvantage/advantage theory, social risk theory (so far rather neglected in social science research), intersectionality, and comparative welfare state research:

While it might be criticised for being complex, one could argue that an understanding of the dynamics of exclusion and inequality in the late working life requires such a sophisticated approach, because these rest in large part on earlier life course experiences and their cumulative impact, the changing profile of social risks and how these are managed and the operation of gendered social policy regimes and gendered life/work courses. Also, how individuals experience late working life transitions is party a function of where they sit in the web of overlapping identities and where these intersect, and the political 
economy which shapes social policy interventions. In sum, it is the combination of hitherto distinct theoretical approaches that represents the major conceptual innovation of EIWO. The linking of late working life exclusion and inequality with intersectionality and, especially its explicit gender focus, can be seen as an entirely new departure. The choice of biographical analyses to understand the operation and impact of social risks, while not new, has rarely been applied to late working life transitions, and not at all to the role of different social policy regimes. In policy terms, the originality of this research lies in the unprecedented multi-layered evidence it will produce and the commitment to the production of change strategies. ${ }^{18}$

Through this complex approach, EIWO could carry forward previous research, which among others, has been already conducted by some of the EIWO scientists particularly for MOPACT WP 3 and EXTEND.

\section{Perfect orientation to the FORTE programme}

To conclude, EIWOs research questions perfectly reflect the essence of two key themes in the FORTE call. The issue of exclusion and inequalities in late working life is key to the challenge of the adaptation of working life to ongoing sociodemographic change - not only regarding age structures but also with respect to immigration (both domestic and international). The creation of conditions for sustainable labour force participation requires the inclusion of preferably all groups of workers including those who are usually underrepresented in the late labour market - women, migrants, those with lower qualification and fragmented careers, as well as in structurally disadvantaged branches and regions - and even the intersections of these.

\section{Methodological limits of the research strategy implementation}

To the extent that EIWO makes use of sophisticated therapy concepts, the question of their empirical verification by means of the existing methodological instruments naturally arises. To the extent that EINWO uses longitudinal data sets, admittedly, these are originally not primarily aimed at EIWOs research questions but cover a much broader spectrum of (partly earlier elaborated research interest). Therefore, answering the central research questions of EIWO by means of their secondary analyses is inevitably limited; it is only possible to evaluate what the primary data provide. This is particularly true for the examination of the intersectionality concept. The more variables required for analytical purposes, the stronger the limits to doing this with the available indicators (e.g., ethnic correlations). It remains to be seen to what extent EIWOs project III (Mechanisms and Origins of Late Working

\footnotetext{
${ }^{18}$ Ibid: page 9.
} 
Life Exclusion) is able to fill these gaps. The aspirations of project III are very high, to say the least.

\section{$5 \quad$ Overall summary and (interim) conclusions}

Three preliminary final conclusions can be drawn:

(1) MOPACT WP 3, EXTEND, and EIWO are three follow-up projects, all with a high application value for the goal of achieving EWL for as many as possible 'in dignity', but each with different 'depths of focus' and thus also in their targeted range.

(2)MOPACT WP 3 and EXTEND are each conducive in different ways to the justification, conceptualisation, and practical implementation of EIWO. EIWO focus, target group identification, and theoretical justification are likely to benefit most from this. However, EIWO undoubtedly has the most sophisticated claim. It remains to be seen whether the chosen mix of methods will meet these expectations.

(3)EIWO takes an explicit life course perspective. EIWOs research areas focus on the labour market as well as pension and retirement policies and asks about preventive concepts to combat social inequalities in their respective embedding in individual's employment biography. In this respect, the expected results might provide indications for a further development of the idea of a social life course policy. This perspective expands the socio-political significance of EIWO, limited to relevant policy areas, even more. 


\section{References}

Amann, A. (1984): Lebenslage und Sozialarbeit. Elemente zu einer Soziologie von Hilfe und Kontrolle. Berlin: Duncker \& Humblot.

Bäcker, G., Naegele, G. \& Bispinck, R. (2020): Sozialpolitik und soziale Lage in Deutschland, 2 Bände. 6. Erweiterte und vollständig überarbeitet Auflage.

Wiesbaden: Springer VS.

Bauknecht, J \& Naegele, G. (2015): Delaying retirement in Germany and Europe. In: Torp, C. (ed.): Challenges of Aging: Retirement, Pensions, and Intergenerational Justice. London: Palgrave Macmillan: 179-204.

BMWE (Bundesminister für Wirtschaft und Energie) (2021) (Hrsg.): Vorschläge für eine Reform der Gesetzlichen Rentenversicherung des wissenschaftlichen Beirats beim Bundesministerium für Wirtschaft und Energie. Berlin.

Börsch-Supan, A. (2016): Das Rentenalter muss atmen können. Download from http://www.mea.mpisoc.mpg.de/index.php?id=218\&no_cache $=1 \& t x \_t t n e w s \% 5 B t t$ _news\%5D=359\&cHash=od969618cddo26704 08a7429934bfcc5 (last access 30.08.2018).

Crenshaw, K. (1991): Mapping the Margins: intersectionality, identity politics and violence against women of color. Stanford Law Review, 43 (6): 1241-1299.

Dannefer, D. (2003): Cumulative Advantage/Disadvantage and the Life Course: Cross-Fertilizing Age and Social Science Theory. Journal of Gerontology, Social Sciences, 58B (6): 327-337.

De Tavernier, W. (2019): Inequality, Social Justice, and Indexing Pension Ages to Life Expectancy. Presentation. IAGG-ER. Gothenburg, Sweden.

Esping-Andersen, G. (1990): The Three Worlds of Welfare Capitalism, Oxford, Polity Press.

Ebbinghaus, B. \& Hofäcker, D. (2013): Reversing Early Retirement in Advanced Welfare Economies. A Paradigm Shift to Overcome Push and Pull Factors. Comparative Population Studies, 38(4): 807-840.

Hess, M., Naegele, G. \&. Bauknecht, J. (2020): Pension and Labour Market policies and the situation of older workers in Germany. In: Naegele, G. \& Hess, M. (Hrsg.): a.a.O.: 69-98.

Hitlin, S. \& Kwon, H.W. (2016): Agency across the Life Course. In: Shanahan, M.J., Mortimer, J.T. \& Kirkpatrick Johnson, M. (eds.) (2016): Handbook of the Life Course. Volume II. Heidelberg, New York, Dordrecht, London: Springer: 431-450. Hofäcker, D. (2015): In line or at odds with active ageing policies? Exploring patterns of retirement preferences in Europe. Ageing and Society, 35(7): 1529.

INQUA (Hrsg.) (2014): Arbeitsfähigkeit erhalten und fördern. Chance für Betriebe und Tarifpolitik. Berlin. Eigenverlag. 
Jensen, P. (2020): Nationale Politiken zur Verlängerung der Lebensarbeitszeit und Auswirkungen auf soziale Ungleichheit. In: Naegele, G. \& Hess, M. (Hrsg.): a.a.O.: 63-68.

Leisering, L. (2003): Government and the Life Course. In: Mortimer, J.Z. \& Shanahan, M.J. (eds.): Handbook of the Life Course. Kluwer Academic, Plenum Publishers. New York: 205-225.

Leßmann, O. (2015): Lebenslage, Capability Set, Teilhabe - Spielraum bei neuen Konzepten von Ungleichheit. In: Romahn, H. \& Rehfeld, D. (Hrsg.): Lebenslagen Beiträge zur Gesellschaftspolitik. Marburg: Metropolis-Verlag: 89-104.

Moehring, K. (2016): Life course regimes in Europe: The structure of individual life courses in comparative perspective. Journal of European Social Policy, 26(2): 124139.

Motel-Klingebiel, A. \& Kelfve, S. (2017): What equality? Life course diversity and inequality in later life in changing Sweden. Innovation in Aging, 1(suppl_1): 845845 .

Naegele, G. (1992): Zwischen Arbeit und Rente. Augsburg: Maro Verlag.

Naegele, G. (2011): Soziale Lebenslaufpolitik - Grundlagen, Analysen und Konzepte. In: Naegele, G. (Hrsg.): Soziale Lebenslaufpolitik. Wiesbaden: VS Verlag für Sozialwissenschaften: 27-85.

Naegele, G. (2021): Late-working life (LWL), exclusion and inequality. National policies and political-economic context in Germany. EIWO position paper. Linköping (forthcoming).

Naegele, G. \& Bauknecht, J. (2018): Strategies ('Action Plan') for Extending Working Lives. Raising Older Worker`s employment rates and intensifying Life Long Learning in later working Life. MOPACT, final report on wp 3. Dortmund: Institut für Gerontologie.

Naegele, G. \& Bauknecht, J. (2019): Extending working lifes. In: Walker, A. (ed.) (2019): a.a.O: 107-142.

Naegele, G. \& Hess, M. (2021): Alte und neue soziale Ungleichheiten bei Berufsaufgabe und Rentenübergang. Ergebnisse des EXTEND Projektes. In: Richter, G. (Hrsg.) (2021): Arbeit und Altern. Eine Bilanz nach 20 Jahren Forschung und Lehre. Baden-Baden: Nomos-Verlag: 141-158.

Naegele, G. \& Walker; A. (2021): Exclusion and inequality in late working life: Evidence for policy innovation towards inclusive extended work and sustainable working conditions in Sweden and Europe. EIWO working paper 1: EIWO `s theoretical perspectives. EIWO-website.

Naegele, G. \& Hess, M. (Hrsg.) (2020): Alte und neue soziale Ungleichheiten bei Berufsaufgabe und Rentenübergang. Ergebnisse des EXTEND-Projektes. Wiesbaden: SpringerVS.

Phillipson, C. (2018): 'Fuller' or 'extended' working lives? Critical perspectives on changing transitions from work to retirement. Ageing \& Society. Cambridge University Press. 
Sen, A. (1991): Inequality reexamined. New York.

Sinclair, D., Moore, K. \& Franklin, B. (2014): Linking state pension age to longevity. Tackling the fairness challenge. London: ILC-UK report.

Walker, A. (2006): Re-examining the Political Economy of Ageing: Understanding the Structure/Agency Tension. In: Baars, J., Dannefer, D., Phillipson, C. \& Walker, A. (eds.): Ageing, Globalisation and Inequality. The New Critical Gerontology. Amityville: Baywood Publishing Company: 59-80.

Walker, A. (2009): Why is Ageing So Unequal? In: Cann, P. \& Dean, M. (eds): Unequal Ageing, Bristol, Policy Press.

Walker, A. (2011) (ed.): FUTURAGE. A Roadmap for European Ageing Research. Sheffield.

Walker, A. (ed.) (2019): The Future of Ageing in Europe. Making an Asset on Longevity. Palgrave Macmillan. Singapore.

Walker, A. (2020): Conclusion. Policy priorities from EXTEND. In: Naegele, G. \& Hess, M. (Hrsg.) (2020): 245-250.

WHO (2002): World Health Organisation: Active Ageing: A Policy Framework. Geneva.

Vouri, J. (2019): Enhancing life-course management throughout working career. NIVA Course: From Age Management to Life Course Management. Presentation. Skodsborg, Denmark: August 2019: FIOH. Helsinki. 